\title{
Spinal cord injuries: a shortened measure of function and mood
}

\author{
C Lundqvist ${ }^{1}$, A Siösteen ${ }^{2}$, L Sullivan ${ }^{2}$, C Blomstrand ${ }^{1}$, B Lind ${ }^{3}$ and M Sullivan ${ }^{4}$ \\ ${ }^{1}$ Departments of Neurology, ${ }^{2}$ Spinal Injuries Unit/Neurosurgery, ${ }^{3}$ Orthopaedic Surgery, and ${ }^{4}$ Health Care Research \\ Unit/Internal Medicine, University of Göteborg and Sahlgrenska University Hospital, Göteborg, Sweden
}

\begin{abstract}
A brief quality-of-life (QL) questionnaire was derived empirically from a cross-sectional study of 98 SCI-patients (83\% men, median age 33.5 years, and median time after injury 2.3 years). A comprehensive general battery of well-established questionnaires (Sickness Impact Profile (SIP), Mood Adjective Check List (MACL), and Hospital Anxiety and Depression (HAD) scale) was combined with a study-specific set of questions to constitute patients' QL. A stepwise analysis model was used to define key areas and questions to be included in a brief SCI-adapted questionnaire. The central areas that independently mattered for SCI-patients' perception of good QL included mental health (no depressive feelings), physical and psychosocial dysfunction (no, or few and minor, limitations in mobility, body care and movement and social interaction), and SCI-related problems (no or little perceived difficulty with loss of independence due to injury). A 22-item questionnaire is suggested for routine clinical follow-up to assess more accurately when optimal treatment and services have been delivered.
\end{abstract}

Keywords: spinal cord injury; quality-of-life assessment; psychometric analysis; short-form questionnaire

\section{Introduction}

A spinal-cord injury usually disables its victims and dramatically changes their ways of living. As life expectancy is steadily improving through modern spinal unit care, ${ }^{1}$ quality-of-life (QL) issues have become more important. ${ }^{2}$ QL, which can be viewed both in terms of handicap and resilience, cannot be distinctly defined, because it is an individual's own, subjective evaluation of the satisfaction derived from his or her life. For healthcare research purposes, applying to health as well as medical interventions, the major aspects of life to be evaluated include physical state and ADL, emotional status and intellectual functioning, social interaction and performance of social roles, and feelings of general satisfaction or well-being. ${ }^{3-5} \mathrm{QL}$, being thus at least partly measurable, is probably more important in relation to how patients adapt to their condition than many of the traditional means of gauging the results of clinical research. ${ }^{6,7}$ In the present study, we have applied modern QL questionnaire technique in a population of permanently-disabled spinal patients with traumatic cord paralysis.

Our intention of developing a suitable measure of how SCI patients feel and function to be used in

Correspondence: M Sullivan clinical practice, followed our observations in recent studies. ${ }^{8}$ Among them are that overall QL and its measurable components do not associate strongly with the degree of neurological impairment; physical functioning correlated closely but inversely. A moderate rate of social adjustment has been observed during the first few years after injury, but little can be inferred from only the length of time after injury. How well patients say they function and feel clearly relates to their overall QL assessment. Our aim is to determine which factors from the comprehensive general battery of well-established questionnaires combined with the SCI-specific questionnaire constitute QL of SCI patients. We plan to define a short measure of QL that may be used for routine clinical follow-up.

\section{Method}

\section{Subjects}

Our present analysis of QL measures is based on data retrieved at cross-sectional follow-up of 98 patients treated consecutively at the Spinal Unit, Sahlgrenska University Hospital. There were 81 men and 17 women with a median age of 33.5 years (range $16-72$ years); the median time after injury was 2.3 years (range $0.1-$ 22.7 years). The distribution between complete and incomplete tetra- and paraplegic subgroups and Frankel classes were unremarkable. ${ }^{8}$ 


\section{Measurements}

\section{Standardized $Q L$ instruments}

I. Quality of Life ( $Q L$ ) recording concerned overall perception of QL on a modified visual analogue scale using a $6 \mathrm{~cm}$ line numbered for reference purposes from 1 to $7 .^{9}$

II. Sickness Impact Profile (SIP) is one of the most widely used and comprehensive general health measures in current use. ${ }^{10}$ Its 136 items are grouped into 12 categories representing a broad spectrum of everyday life activities: Ambulation, Body care and movement, Mobility, Emotional behaviour, Social interaction, Alertness behaviour, Communication, Work, Home management, Recreation and pastimes, Sleep and rest, and Eating. Respondents have to check each item that describes a dysfunction in relation to their health at the time. A weighting system allows a quantification of the severity of impact. Scores are calculated and expressed as per cent of maximum dysfunction for each category, two dimensions and an overall index.

III. Mood Adjective Check List (MACL) frequently used to supplement the SIP, measures several aspects of emotional status and mental well-being. ${ }^{11}$ It contains bipolar factors of each mood expression. We considered its three main dimensions as adequate for the present study: they were Pleasantness/ unpleasantness, Activation/deactivation, and Calm- ness/tension and they comprise 38 items; each allows a 1-to-4 response.

IV. Hospital Anxiety and Depression (HAD) scale includes 2 dimensions, 7 items concerning anxiety and 7 depression with a 0 -to- 3 scale. ${ }^{12}$ The scale is intended to screen for psychiatric morbidity in the somatically ill.

\section{SCI-specific instruments}

I. SCI Problem scale defined patients' perceptions of dependence (3 items), complications (5 items) and social stigma ( 2 items). The response format was a 0 to-3 scale from 'very difficult' to 'not at all difficult'. The psychometric properties and clinical relevance of the 10 -item scale are described elsewhere. ${ }^{8}$

II. Sexual Interest and Satisfaction (SIS) scale aggregates 7 items, scored to form a scale with confirmed consistency. ${ }^{13}$

\section{Statistical method}

A forward stepwise analysis model was used to explore the key areas and questions of a brief QL questionnaire. Measures of function, mood and SCI-specific problems, in all 22 composite variables were selected as possible predictors of patients' overall QL rating. Correlations were checked by Pitman's permutation test. ${ }^{14}$ Second, the ultimate strength of predictors was determined by partial correlation analysis (Mantel's

Dependent variable: overall QL rating

\begin{tabular}{|c|c|c|c|c|c|}
\hline Step & SIP & HAD scale & MACL & Problem scale & sis scale \\
\hline $\begin{array}{l}\text { 1. Independent } \\
\text { variables } \\
\text { entered }\end{array}$ & $\begin{array}{l}15 \text { cate- } \\
\text { gories } \\
\text { (136 items) } \\
\quad \downarrow\end{array}$ & $\begin{array}{l}2 \text { cate- } \\
\text { gories } \\
\text { (14 items) } \\
\qquad\end{array}$ & $\begin{array}{l}3 \text { cate- } \\
\text { gories } \\
\text { (38 items) } \\
\qquad\end{array}$ & $\begin{array}{l}1 \text { cate- } \\
\text { gory } \\
\text { (10 items) } \\
\downarrow\end{array}$ & $\begin{array}{l}1 \text { cate- } \\
\text { gory } \\
\text { (7 items) } \\
\quad \downarrow\end{array}$ \\
\hline \multicolumn{6}{|l|}{$\begin{array}{l}\text { 2. Potentially } \\
\text { powerful }\end{array}$} \\
\hline $\begin{array}{l}\text { categories; } \\
\text { Pitman's } \\
\text { test, } p<0.0001\end{array}$ & $\begin{array}{l}5 \text { cate- } \\
\text { gories } \\
\text { (70 items) } \\
\qquad \downarrow\end{array}$ & $\begin{array}{l}1 \text { cate- } \\
\text { gory } \\
\text { ( } 7 \text { items) }\end{array}$ & $\begin{array}{l}2 \text { cate- } \\
\text { gories } \\
\text { (28 items) } \\
\quad \downarrow\end{array}$ & $\begin{array}{c}1 \text { cate- } \\
\text { gory } \\
(10 \text { items ) } \\
\downarrow\end{array}$ & $\begin{array}{l}1 \text { cate- } \\
\text { gory } \\
\text { (7 items) } \\
\quad \downarrow\end{array}$ \\
\hline $\begin{array}{l}\text { 3. Powerful } \\
\text { categories; } \\
\text { Mantel's } \\
\text { test, p<0.05 }\end{array}$ & $\begin{array}{l}3 \text { cate- } \\
\text { gories } \\
\text { ( } 53 \text { items) }\end{array}$ & $\begin{array}{l}1 \text { cate- } \\
\text { gory } \\
\text { ( } 7 \text { items) }\end{array}$ & $\begin{array}{l}\text { (no indepen- } \\
\text { dent predic- } \\
\text { tive value) }\end{array}$ & $\begin{array}{l}1 \text { cate- } \\
\text { gory } \\
\text { (10 items) }\end{array}$ & $\begin{array}{l}\text { (no indepen- } \\
\text { dent predic- } \\
\text { tive value) }\end{array}$ \\
\hline $\begin{array}{l}\text { 4. Multiple } \\
\text { regression }\end{array}$ & & $\begin{array}{l}60 \% \text { expla } \\
\text { (5 catego }\end{array}$ & $\begin{array}{l}\text { d variance } \\
\text { s; } 70 \text { items) }\end{array}$ & & \\
\hline
\end{tabular}

SIP = Sickness Impact Profile

HAD $\quad$ Hospital Anxiety and Depression scale

Figure 1 Main steps in the prediction of quality of life (QL) perception by health status assessments. Phase I: reduction of categories 
test). ${ }^{15}$ A third step comprised a multiple correlation analysis (a parametric procedure) to give the variance of the QL rating explained by these predictors. The same stepwise method of analysis was used again to identify the specific questions that were to constitute the brief QL instrument. Its reliability was calculated according to standard psychometric methodology, Cronbach's alpha (coefficients above 0.70 for internal consistency) and principal component analysis (factor loadings above 0.40 for unidimensionality). ${ }^{16}$

\section{Results}

Prediction of overall $Q L$ perception

The main steps of the prediction analysis can be seen in Figure 1. Ten of 22 categories or dimensions correlated strongly with the overall QL-rating $(P<0.0001$; range of $\left.r^{2}=0.40-0.66\right)$. Five of these categories were prominent according to the patient correlation procedure. They explained $60 \%$ of the overall QLrating and concerned degrees of depressive feelings, functional limitations in mobility, body care and movement, and social interaction and perception of problems specific to SCI-patients (Figure 1).

\section{SCI-adapted $Q L$ instrument}

The questions within each of the five prominent categories were then analyzed in order to reduce the number of questions (not shown in the Figure) Twenty-two of 70 items correlated strongly with QL $(P<0.0001)$. After partial correlation, we further reduced the number of indicative items to 9 that,

Table 1 Brief quality of life-QL questionnaire for SCI subjects, 22-item version

\begin{tabular}{|c|c|c|c|}
\hline & $\begin{array}{l}\text { Items in scale in descending } \\
\text { order of importance for } \\
\text { composite variable }\end{array}$ & $\begin{array}{l}\text { Weight of } \\
\text { score }\end{array}$ & $\begin{array}{l}\text { Composite variable } \\
\text { (range of score, } \\
\text { Cronbach's alpha) }\end{array}$ \\
\hline 1. & $\begin{array}{l}\text { I am doing fewer social activities } \\
\text { with groups of people (SI) }\end{array}$ & 3.6 & \\
\hline 2. & $\begin{array}{l}\text { I get dressed only with someone's } \\
\text { help (BCM) }\end{array}$ & 88 & \\
\hline 3. & $\begin{array}{l}\text { I am getting around only within } \\
\text { one building }(\mathrm{M})\end{array}$ & 8.6 & \\
\hline 4. & My sexual activity is decreased ( $\mathrm{SI})$ & 5.1 & \\
\hline 5. & I am going out less to visit people (SI) & 4.4 & \\
\hline 6. & $\begin{array}{l}\text { I do not move into or out of bed or } \\
\text { chair by myself but am moved by a person } \\
\text { or mechanical aid (BCM) }\end{array}$ & 12.1 & $\begin{array}{l}\text { Dysfunction-SIP } \\
(0-100 \%, \alpha=0.85)\end{array}$ \\
\hline 7. & I stay home most of the time $(\mathrm{M})$ & $\begin{array}{r}12.1 \\
6.6\end{array}$ & \\
\hline 8. & I am staying in bed more $(\mathrm{M})$ & 8.1 & \\
\hline 9. & $\begin{array}{l}\text { I am cutting down the length of visits } \\
\text { with friends (SI) }\end{array}$ & 4.3 & \\
\hline 10. & $\begin{array}{l}\text { I make difficult moves with help, eg } \\
\text { getting into or out of cars, bath tubs (BCM) }\end{array}$ & 8.4 & \\
\hline $\begin{array}{l}1 . \\
2 .\end{array}$ & $\begin{array}{l}\text { I look forward with enjoyment to things } \\
\text { I can laugh and see the funny side of things }\end{array}$ & $\begin{array}{l}0-3 \\
0-3\end{array}$ & \\
\hline 3. & I have lost interest in my appearance & $3-0$ & Depression-HAD \\
\hline 4. & I feel cheerful & $0-3$ & $(0-18, \alpha=0.85)$ \\
\hline 5. & I still enjoy the things I used to enjoy & $0-3$ & \\
\hline 6. & I feel as I am slowed down & $3-0$ & \\
\hline 1. & $\begin{array}{l}\text { How difficult is it not being able of walk } \\
\text { or move freely? }\end{array}$ & $3-0$ & \\
\hline 2. & $\begin{array}{l}\text { How difficult is it being in need of help } \\
\text { with many things? }\end{array}$ & $3-0$ & Problem-SCI \\
\hline 3. & $\begin{array}{l}\text { How difficult is it not being able to do } \\
\text { things when wanted? }\end{array}$ & $3-0$ & $(0-18, \alpha=0.86)$ \\
\hline 4. & $\begin{array}{l}\text { How difficult is it not being able to } \\
\text { hide oneself in a crowd? }\end{array}$ & $3-0$ & \\
\hline 5. & $\begin{array}{l}\text { How difficult is it having intestinal } \\
\text { problems? }\end{array}$ & $3-0$ & \\
\hline 6. & How difficult is it having pain? & $3-0$ & \\
\hline
\end{tabular}

Overall QL rating: Dysfunction-SIP $\times \mathrm{W}_{1}+$ Depression-HAD $\times \mathrm{W}_{2}+$ Problem-SCI $\times \mathrm{W}_{3} ; 63 \%$ explained variance. $\mathrm{W}_{1}$ : weight of variable in linear combination. (SIP): Sickness Impact Profile, (SI): Social Interaction, (BCM): Body Care and Movement, (M): Mobility, (HAD): Hospital Anxiety and Depression 
grouped into three categories, explained almost twothirds of the QL rating (Table 1). The 22-item version was adapted because of better psychometric properties (higher Cronbach's alpha and factor loadings) although the 9-item version was as good in the level of explained variance. The central areas that independently mattered for SCI patients perception of good QL included mental health (no depressive feelings), physical and psychological dysfunction (no, or few and minor, limitations in mobility, body care and movement and social interaction), and SCI-related problems (no or little perceived difficulty with loss of independence due to injury). The specific questions and their aggregation to scales can be seen in Table 1 .

The stability of the 22- and 9-item questionnaires was verified in clinical analyses. In the tetraplegic, paraplegic, complete and incomplete lesion subgroups, each version of the questionnaire accounted for a similar part of the variance of overall QL ratings as was seen in the total sample (range of $r^{2}=0.61-0.69$ ).

\section{Discussion}

Any comprehensive assessment of QL in populations of chronically-ill or impaired patients requires the patients themselves to assess various aspects of their QL, but clinicians have had reason to question the validity of such 'soft' information. ${ }^{17}$ Their reasons have included conceptual, methodologic, practical, and attitudinal objections; scepticism about the validity and importance of self-rated health; preferences for physiologic outcomes or death rates; and unfamiliarity with questionnaire scores. ${ }^{18}$ However, techniques developed in recent years for gauging health-related QL have confirmed psychometric properties and clinical relevance. ${ }^{3-12,19-21}$ Dominant strategies have been outlined and both general and disease-specific measures have been constructed and validated. Health profiles are thus capable of defining components of QL systematically and consistently. The SIP, seemingly the least fallible general inventory, has been considered appropriate in diverse clinical settings including chronic neurological conditions, peripheral and central, and with or without pain. ${ }^{22-24}$ For this reason, we decided to use it as a basic measure in the present study, in which we made supplementary use of the MACL and HAD scales to determine different detailed aspects of emotional states and mental well-being. We found these general questionnaires well suited to our purpose of showing new information on SCI patients' perceptions of how they felt and functioned in daily life. ${ }^{8}$ In addition, two specific scales, SCI Problem scale and SIS scale, were developed and tested. . $^{8,13}$

We followed a new path of analysis in order to find which parts of a battery of health-related standard questionnaires could most closely predict patients' overall QL assessment. Through the stepwise model (Figure 1), we identified particular areas as being capable of independently predicting the QL assessments. We then identified single questions within these areas that substantially predicted the QL assessments (Table 1). We could thus derive our short SCI-adapted questionnaire in two versions, a 22-item version before the partial correlation and a 9-item version after. Both versions explained almost two-thirds of the variance of overall QL ratings, a finding that was consistent in the clinical subgroups. As expected, the reliability values of the 22-item version were somewhat higher and well above minimum psychometric criteria for scale development. It is therefore recommended for routine clinical follow-up to serve as a 'subjective thermometer' to get a more accurate assessment once optimal treatment and services have been provided. For research purposes, the original standard measures are still the most suitable.

\section{Note added in proof}

The questionnaire and scoring instructions are available from the corresponding author.

\section{Acknowledgements}

The investigation was supported by grants from the Swedish Council for Planning and Coordination of Research (No. 880264:3), the Ministry of Health and Social Affairs-Commission for Social Research (No. E88/ 11), the Norrbacka-Eugenia Foundation and Greta and Einar Asker Foundation.

\section{References}

1 DeVivo MJ et al. A cross-sectional study of the relationship between age and current health status for persons with spinal cord injuries. Paraplegia 1992; 30: 820-827.

2 Rogerson RJ. Environmental and health-related quality of life: conceptual and methodological similarities. Soc Sci Med 1995; 41: $1373-1382$

3 Stewart AL, Ware JE, (eds). Measuring Functioning and WellBeing. The Medical Outcomes Study Approach. Duke University Press, Durham. 1992.

4 Patrick DL, Erickson P. Assessing Health-Related Quality of Life for Clinical Decision-Making. In: Walker SR, Rosser RM, (eds). Quality of Life Assessment-Key Issues in the 1990s. Kluwer Academic Publishers, Lancaster, 1993; pp. 11-63.

5 Ware JE. The status of health assessment 1994. Annu Rev Public Health 1995; 16: $327-354$.

6 Sullivan M. Quality of life assessment in medicine. Concepts, definitions, purposes, and basic tools. Nord J Psychiatry 1992; 46: $79-83$

7 McSweeny AJ, Creer TL. Health-related quality-of-life assessment in medical care. Disease-a-Month 1995; 41: 1-72.

8 Lundqvist $\mathrm{C}$ et al. Spinal cord injuries. Clinical, functional and emotional status. Spine 1991; 16: $78-83$.

9 Schipper H, Clinch J, McMurray A, Levitt M. Measuring the quality of life of cancer patients: the Functional Living Index Cancer: development and validation. J Clin Oncol 1984; 2: $472-$ 483.

10 Bergner M, Bobbitt RA, Carter WB, Gilson BS. The Sickness Impact Profile: development and final revision of a health status measure. Med Care 1981; 19: 787-805.

11 Sjöberg L, Svensson E, Persson L-O. The measurements of mood. Scand J Psychol 1979; 20: $1-18$.

12 Zigmond AS, Snaith RP. The Hospital Anxiety and Depression scale. Acta Psychiatr Scand 1983; 67: $361-370$ 
13 Siösteen A et al. Sexual ability, activity, attitudes and satisfaction as part of adjustment in spinal cord-injured subjects. Paraplegia 1990; 28: $285-295$.

14 Bradley JW. Distribution-Free Statistical Tests. Prentice-Hall, London: 1968; pp. 68-86.

15 Mantel N. Chi-square test with one degree of freedom: extensions of the Mantel-Haenszel procedure. J Am Stat Assoc 1963; 58: $690-700$

16 Nunnally NC, Bernstein IH. Psychometric Theory 3rd ed. McGraw-Hill, New York: 1994

17 Gill TM, Feinstein AR. A critical appraisal of the quality of quality-of-life measurements. JAMA 1994; 272: 619-626.

18 Deyo RA, Patrick DL. Barriers to the use of health status measures in clinical investigation, patient care, and policy research. Med Care 1989; 27: S254-S268.

19 Bowling A. Measuring Health. A Review of Quality of Life Measurement Scales. Open University Press, Milton Keynes, 1991.
20 Bowling A. Measuring Disease. A Review of Disease-Specific Quality of Life Measurement Scales. Open University Press, Buckingham, 1995.

21 Shumaker SA, Berzon R (ed). The International Assessment of Health-Related Quality of Life: Theory, Translation, Measurement \& Analysis. Rapid Communications, Oxford, 1995.

22 Augustinsson LE, Sullivan L, Sullivan M. Chronic pain in functional neurosurgery: function and mood in various diagnostic groups with reference to epidural spinal electrical stimulation. Schmerz/Pain/Douleur 1989; 10: $30-40$.

23 Sullivan M. The Sickness Impact Profile (SIP): an instrument for overall health assessment; a basic evaluation. J Drug Ther Res 1988; 13: $167-169$

24 Zeldow PB, Pavlov M. Physical and psychosocial functioning in multiple sclerosis: descriptions, correlations, and a tentative typology. Br J Med Psychol 1988; 61: 185-195. 